\title{
Optimizing the machining variables in CNC turning of aluminum based hybrid metal matrix composites
}

\author{
Ravi Butola ${ }^{1}$ [D . Vaibhav Sharma ${ }^{1}$ Susheem Kanwar ${ }^{1} \cdot$ Lakshay Tyagi $^{1} \cdot$ Ranganath M. Singari $^{1} \cdot$ Mohit Tyagi $^{2}$
}

Received: 18 March 2020 / Accepted: 26 June 2020 / Published online: 8 July 2020

Published online: 08 July 2020

(c) Springer Nature Switzerland AG 2020, corrected publication 2023

\begin{abstract}
Aluminum based hybrid metal matrix composites (HMMC) are being employed nowadays in automobile, aeronautical, sports equipment etc. In this study, three different Al6063 based hybrid metal matrix composites (HMMC) samples having reinforcement with $3 \%, 6 \%$ and $9 \%$ by weight respectively are fabricated using stir casting method. Reinforcements used are waste products, namely, jute ash, groundnut shell and sugarcane. Surface roughness of these fabricated composite are is tested by varying machining parameters. The design of experiment is constructed by Taguchi method using three factors and two level, with L8 orthogonal array in which surface roughness is the output response parameter. These recorded results are analysed using analysis of variance and optimization of process parameters is done using response surface methodology and genetic algorithm. The Genetic algorithm optimization is achieved within 102 generations which is quite fast. On comparing it was found that results obtained from GA closely agreed with those obtained from the Response surface methodology.
\end{abstract}

Keywords Composite · Sugarcane ash · Groundnut shell ash · Jute ash · Genetic algorithm · Taguchi

\section{Introduction}

We use turning operation in order to generate workpieces of rotational geometry by removing material in the form of chips. Turning is extensively utilized in the manufacturing industry and therefore there is an imminent need to optimize it from the point of view of cutting high performance dynamics, workpiece materials and cutting tools. Industrial processes can be optimized by Taguchi method, Scatter search, Genetic algorithm, Fuzzy logic, Langrange's method, Geometric programming. Composites of aluminium exhibit desired physical and mechanical properties like resistance to corrosion etc. So, these materials are used extensively in automotive, aerospace, defense and sport equipment industries [1].

Metal matrix composite reinforced with particles (PRMMC) is formed when we combine the matrix made of metal with reinforcement particles to enhance the attributes of the composite with respect to its base components. A whole host of factors like matrix-reinforcement bonding, simple structure, feasibility in terms of processing, etc. make aluminium-based metal matrix (Al-MMC) one of the most studied materials. These reinforcements lead to superior specific stiffness, a decrease in density, improved fatigue resistance, etc. [2-10]. Stir casting is a cheap and simple method for fabricating HMMCs but despite that it has limitations caused by the poor dispersal of the reinforcement in the matrix [11, 12]. The reinforcement particle size which results in agglomeration and decreases wettability of reinforcements within the melt is responsible for this [13]. It was found that reinforcement like boron carbide is superior to rice husk ash and silicon carbide when it comes to increasing the micro-hardness

Ravi Butola, ravibutola33855@gmail.com|'Mechanical Engineering Department, Delhi Technological University, New Delhi, India. ${ }^{2}$ Department of Industrial and Production Engineering, Dr. B. R. Ambedkar National Institute of Technology, Jalandhar, India. 
values [14]. Garg et al. [15] found that fabrication of $\mathrm{ZrSiO}_{4 \mathrm{p}} / 6063$ Aluminium MMC led to improved hardness and tensile properties. Friction Stir Process (FSP) is usually responsible for increasing grain size and fineness of particles [16]. Influence of RHA was observed on AA6061 aluminium matrix composite and it was found that RHA particles result in very good interfacial bonding. Organic ashes are used as reinforcements in aluminium metal matrix composites to make it hybrid and it improves certain properties of the composite.

A factor of significant importance in cutting is surface quality. AISI 4340 alloy is a high strength steel and is applied in various fields like aerospace, automobile etc. for use as spindles, axle, gears, couplings etc. [17]. A considerable amount of research is being carried out on turning process optimization in the modern era. Ravi et al. found surface properties of mild steel to be comparatively superior on wet turning as compared to dry turning. Surface roughness of workpiece material gets affected due to losses in turning operation [18]. Siddesh et al. [19] experimented turning on Al2219 and its composites and found that cutting speed was inversely proportional to surface roughness caused by lesser contact between tool and workpiece. Nataraj and Balasubramanian [20] revealed that it HMMC are difficult to machine because of their particulates which are abrasives and form an edge of cutting while machining inducing vibrations and wear of tool. Devinder et al. [21] looked at the role of input variables on cutting force and roughness of machined surface obtained upon performing the turning operation on Al6061-SiC-Gr hybrid nanocomposite using response surface methodology. It was found that depth of cut and feed rate had a significant impact on both cutting force and surface roughness of the machined material and they affected both of them identically. Bains et al. [22] reviewed synthesis as well as machining of MMC and concluded that a great amount of cutting speed, and lower amount of depth of cut as well as feed rate to be essential for better surface finish of the material. They also found that electric discharge machining is one process under extensive research in unconventional machining in past years. Pul [23] found surface roughness (SR) to be inversely proportional to cutting speed and directly proportional to feed rate.

Suresh et al. [24] looked into the result of various cutting variables and time taken for machining on the characteristics of AISI 4340 alloy steel of high strength during machining with the help of coated carbide inserts, found from RSM technique that to minimize the machining characteristics, machining variables and time need to be minimum. Vaibhav et al. [25] carried out a comprehensive review of various optimization techniques like Taguchi, response surface methodology (RSM) and grey fuzzy algorithm applied to CNC turning to find the optimal values of machining variables. They found MRR to be directly proportional to feed and depth of cut but inversely proportional to cutting speed. Baburaj et al. [26] explained the impact of turning operation with a much higher cutting speed on the surface roughness of Al-SiC-fly ash hybrid metal matrix composite. From analysis of variance they revealed that cutting speed had the maximum impact on surface roughness which in turn was succeeded by feed and depth of cut, while nose radius had least influence on it. Dinaharan et al. [27] found that addition of fly ash to AA6061 composite increased its microhardness and was homogenously distributed without giving rise to any agglomerations. Taguchi method is one of the ideal methods to optimize machining parameters as a robust standard for different situations helping in achieve the objective of maximum production rate and minimum cost of production. This is achieved by minimizing SR and maximizing MRR. Most researchers found feed rate to have the greatest contribution in optimization of turning process. Butola et al. [28] studied drill bit assisted abrasive flow machining and found that the profile resulted in improvement of surface finish and material removal response parameter. Sonowal et al. studied machinability of HMMCs and its further improvement, observed that for effective machining; it is required to choose the appropriate machining process. For optimal surface roughness the most significant factor is the feed rate followed by the depth of cut [29].

The purpose of this paper, involves synthesising three different Al6063 HMMC samples reinforced with 3\%, 6\% and $9 \%$ by weight respectively. The fabricated composites are tested for their surface roughness by varying process parameters. The machining parameters are then optimized by making use of the genetic algorithm (GA) and also with response surface methodology. GA is probabilistic in nature rather than deterministic which makes it quite accurate. Whereas, response surface methodology is a mathematical and statistical technique used for analysing data. Reinforcements used are waste products, namely, the ashes of jute, groundnut shell and sugarcane.

\section{Materials and methods}

The ashes of sugarcane, groundnut shell and jute shown in Fig. 1, were utilized as reinforcement in Al-HMMC. The ashes were prepared after burning, ball milling and passing the remain through sieve of varying mesh number. The size of the reinforcement spanned the range from a low of 53 micrometres to a high of 600 micrometres corresponding to ASTM 30 to ASTM 270. Most amount of particles were collected in the sieve with ASTM number 200, viz, the one which allow particles of only 75 micrometres or smaller to pass through for sugarcane ash (SCA) and groundnut shell ash (GSA). For jute ash (JA) most particles 
Fig. 1 Powdered ash from various sources used as reinforcement a sugarcane $\mathbf{b}$ groundnut shell c jute

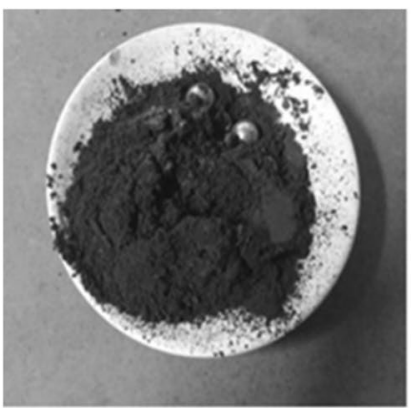

SUGARCANE ASH

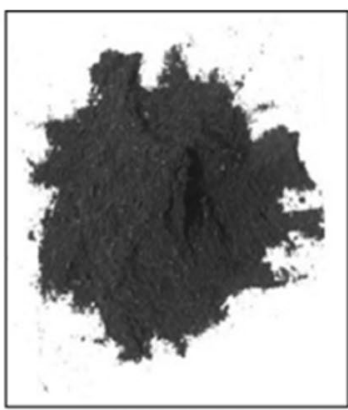

GROUNDNUT SHELL ASH

b

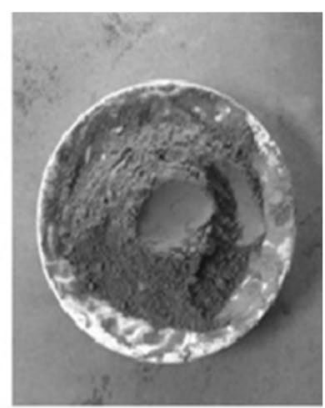

JUTE ASH

C were collected in the sieve with ASTM number 270, or the sieve which only allows particles with size less than 53 micrometres to pass through.

\subsection{Stir casting method}

Al-MMC are produced using 3 different techniques, namely, solid phase technique, liquid phase technique and semi-solid phase techniques. They enable us to determine attributes like microstructure of the composites and the interfacial bond between its components. Solid phase technique is quite expensive since it involves powdered raw materials etc. On the other hand the liquid phase technique is economically viable. It employs a high-temperature melt to cause a thermal deterioration of the reinforcement caused due to the chemical reaction between the reinforcement and the melt.

The HMMCs were fabricated using stir casting technique, the setup and model is shown in Fig. 2. Aluminium 6063 was preheated and added to the muffle furnace while being continuously stirred for 6 to $7 \mathrm{~min}$ in order to achieve uniform distribution. The temperature of the melt taken was $700{ }^{\circ} \mathrm{C}$ during addition of reinforcement, which was dispersed using the vortex method. The molten mixture was subsequently sent to a preheated mould at a temperature of $680^{\circ} \mathrm{C}$ and allowed to solidify. The samples were moulded in the geometry of a cylindrical with diameter and length being $30 \mathrm{~mm}$ and $100 \mathrm{~mm}$ respectively. The composite was fabricated using Al 6063 as the matrix and reinforcements used were SCA (Sugarcane Ash), GSA (Groundnut Shell Ash), JA (Jute ash). The composites were fabricated taking reinforcement in different weight proportion of $3 \%, 6 \%$ and $9 \%$., the reinforcement were very properly spread throughout the composite. Pardeep et al. [30] found that graphite reinforcement at 12\% in aluminium MMC was properly distributed. Swamy et al. [7] found that graphite addition in excess of $7 \%$ impairs the mechanical properties of composites. The phenomenon remains the same for other reinforcements as well including natural reinforcements.
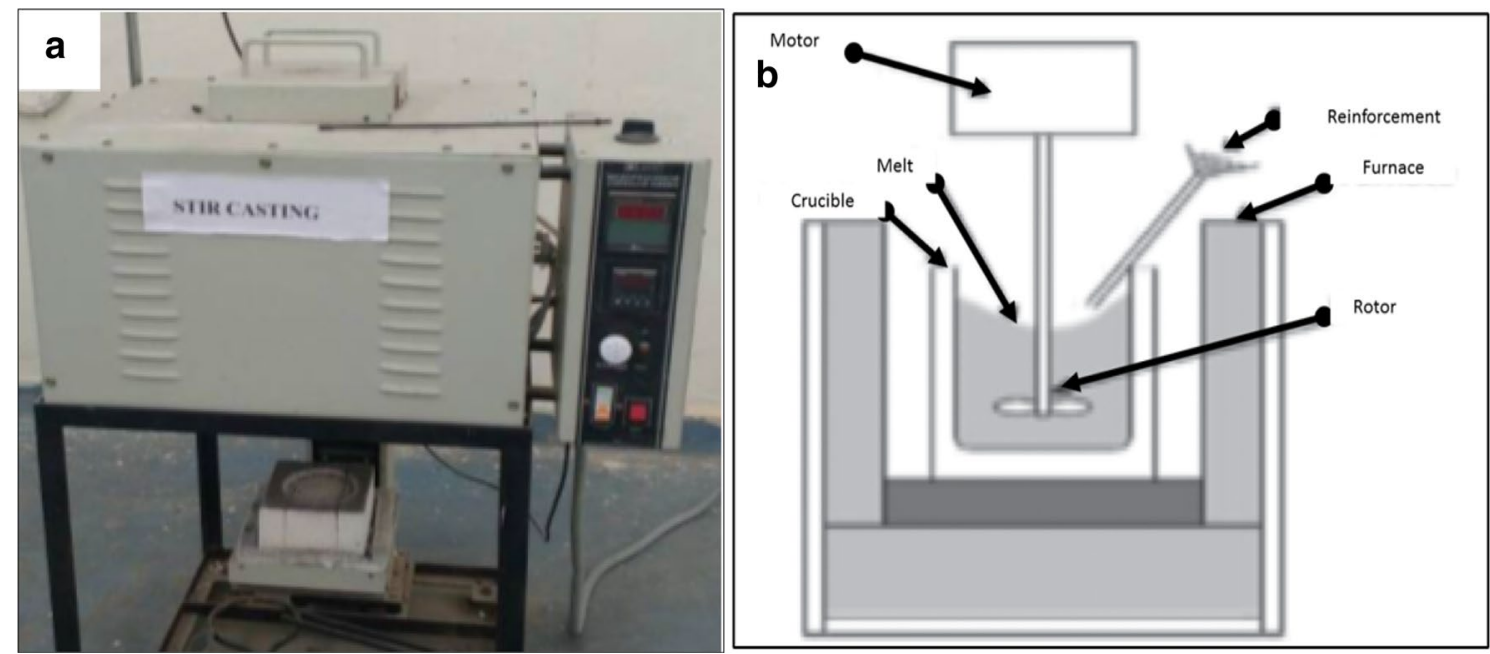

Fig. 2 Stir casting furnace $\mathbf{a}$ setup $\mathbf{b}$ model 


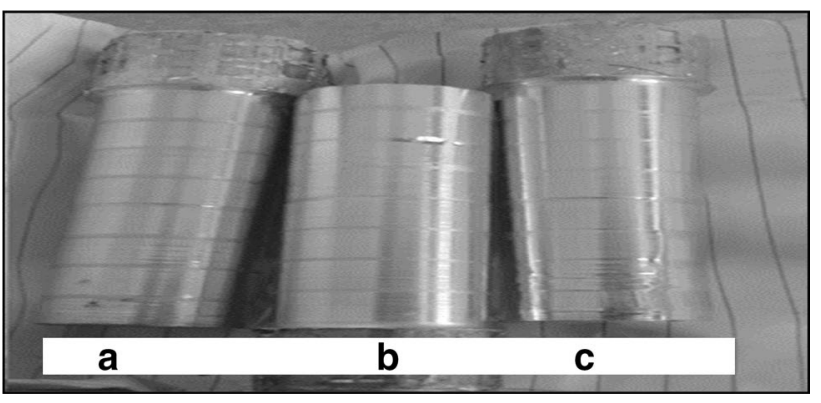

Fig. 3 Workpieces after CNC turning. a Al-HMMC with $3 \%$ reinforcements b Al-HMMC with $6 \%$ reinforcements c Al-HMMC with $9 \%$ reinforcements

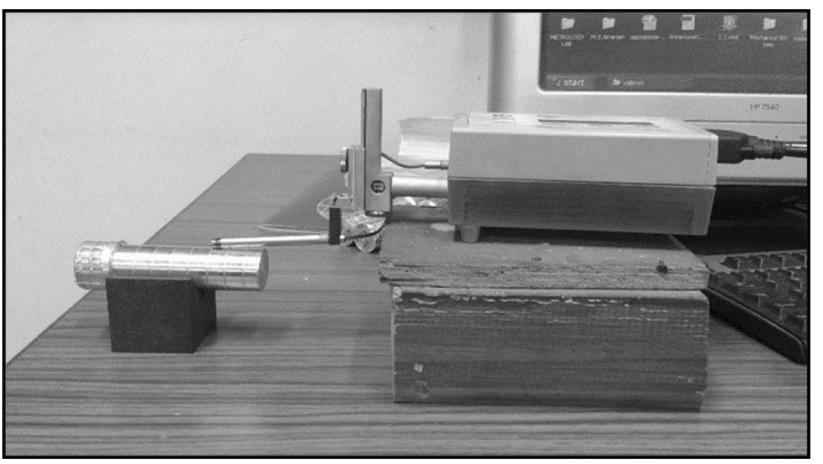

Fig. 4 Surface roughness measurement using Surtronic 3+

\subsection{Surface roughness evaluation}

In this study the turning operation was performed on Al-HMMC workpieces by using a CNC turning machine (LMW LL20T L3) present in the Metal Cutting Lab at Delhi Technological University. The workpiece formed was a $100 \mathrm{~mm} \times 30 \mathrm{~mm}$ cylinder as shown in Fig. 3. An uncoated tungsten carbide (CNMG 120404-THM) was utilized as a cutting tool in the dry turning operation. The finished surface was used to evaluate the surface roughness. A Taylor/ Hobson Surtronic $3+$ was used for this purpose displayed in Fig. 4.

\subsection{Optimization technique}

Taguchi L8 orthogonal array was developed using the MINITAB software package. Three different parameters, namely, speed, feed and depth of cut were taken as the input variables. This was a two level and three factor design of experiment shown in Table 1. Surface roughness was considered as the output whereas, the input varied between maximum and minimum values. ANOVA was used for the analysis purpose as it helps in establishing the percentage significance of each input value for a given
Table 1 Input machining parameter

\begin{tabular}{llll}
\hline S. no. & Designation & $\begin{array}{l}\text { Input machining vari- } \\
\text { ables }\end{array}$ & Control factor levels \\
\hline 1 & A & Cutting speed (S) (rpm) & 1000,1500 \\
2 & B & Feed rate (F) (mm/rev) & $0.15,0.30$ \\
3 & C & $\begin{array}{l}\text { Depth of cut (DoC) } \\
\text { (mm) }\end{array}$ & $0.3,0.6$ \\
\hline
\end{tabular}

Table 2 Optimization of the output parameter for Al-HMMC with $3 \%$ reinforcement

\begin{tabular}{llllll}
\hline Speed & Feed & Depth of cut & Surface SR & S/N ratio & Mean \\
\hline 1000 & 0.15 & 0.3 & 1.46 & -3.28706 & 1.46 \\
1000 & 0.15 & 0.6 & 2.54 & -8.09667 & 2.54 \\
1000 & 0.3 & 0.3 & 1.86 & -5.39026 & 1.86 \\
1000 & 0.3 & 0.6 & 2.45 & -7.78332 & 2.45 \\
1500 & 0.15 & 0.3 & 1.53 & -3.69383 & 1.53 \\
1500 & 0.15 & 0.6 & 2.57 & -8.19866 & 2.57 \\
1500 & 0.3 & 0.3 & 2.31 & -7.27224 & 2.31 \\
1500 & 0.3 & 0.6 & 3.07 & -9.74277 & 3.07 \\
\hline
\end{tabular}

output. Signal to Noise $(\mathrm{S} / \mathrm{N})$ ratio helps us in obtaining the optimized values of the machining variables. In this study, response surface methodology was also used to develop a mathematical model which was further used to optimize the input process parameters. Another optimization technique utilized is the genetic algorithm (GA) technique worked using the MATLAB optimization toolbox. GA is modelled on the evolutionary process that takes place in living organisms. It starts with a random initial population which then undergoes reproduction, crossover and mutation in this sequence. Some of the members in the population are selected to be parents and are used to produce offspring for the next generation. This is an iterative process, which keeps on happening till the optimized solution is obtained [31-33].

\section{Results and discussion}

\subsection{For Al-HMMC with 3\% reinforcements}

Upon analysing the $\mathrm{S} / \mathrm{N}$ ratios from Table 2 , it was found that minimum surface roughness of Al6063-3\%(SCA-GSAJA) HMMC is correlated with a speed, feed and depth of cut of $1000 \mathrm{rpm}, 0.15 \mathrm{~mm} / \mathrm{rev}$ and $0.3 \mathrm{~mm}$ respectively. These represent the optimal values for this process. From analysis of variance (ANOVA) shown in Table 3 we see that depth of cut had $68.67 \%$ contribution, feed rate had $14.42 \%$ contribution and cutting speed had $7.81 \%$ contribution. The 
Table 3 ANOVA for Al-HMMC with $3 \%$ reinforcement

\begin{tabular}{llllllc}
\hline Source & DF & SS & MS & F & P & Contribution (\%) \\
\hline Speed & 1 & 0.17111 & 0.17111 & 3.43 & 0.138 & 7.807573497 \\
Feed & 1 & 0.31601 & 0.31601 & 6.34 & 0.065 & 14.41921162 \\
Depth of cut & 1 & 1.50511 & 1.50511 & 30.20 & 0.005 & 68.67662291 \\
Error & 4 & 0.19935 & 0.04984 & & & 9.096135682 \\
Total & 7 & 2.19159 & & & & \\
\hline
\end{tabular}

Table 4 Optimization of the output parameter for Al-HMMC with $6 \%$ reinforcement

\begin{tabular}{llllll}
\hline Speed & Feed & Depth of cut & SR & S/N ratio & Mean \\
\hline 1000 & 0.15 & 0.3 & 1.2 & -1.58362 & 1.20 \\
1000 & 0.15 & 0.6 & 1.44 & -3.16725 & 1.44 \\
1000 & 0.3 & 0.3 & 1.54 & -3.75041 & 1.54 \\
1000 & 0.3 & 0.6 & 2 & -6.02060 & 2.00 \\
1500 & 0.15 & 0.3 & 1.51 & -3.57954 & 1.51 \\
1500 & 0.15 & 0.6 & 1.93 & -5.71115 & 1.93 \\
1500 & 0.3 & 0.3 & 1.87 & -5.43683 & 1.87 \\
1500 & 0.3 & 0.6 & 2.41 & -7.64034 & 2.41 \\
\hline
\end{tabular}

most significant factor is depth of cut succeeded by feed rate and cutting speed.

Objective function: $y=[1.07000000 e-035.48333333 e+002.25000000 e+00]$

$$
* \times+-1.5724999999999398
$$

This is the objective equation for the Al-HMMC sample with $3 \%$ reinforcement. It is obtained using python software by using the $L 8$ dataset consisting of various combinations of input values and their corresponding values of output values.

\subsection{For Al-HMMC with $6 \%$ reinforcements}

Table 4 shows the optimization of output parameters, a higher $\mathrm{S} / \mathrm{N}$ ratio response represents minimum SR. Thus, optimum machining parameter for this workpiece of Al6063-6\%(SCA-GSA-JA) are correlated to cutting speed, feed rate and depth of cut of $1000 \mathrm{rpm}, 0.15 \mathrm{~mm} / \mathrm{rev}$ and $0.3 \mathrm{~mm}$ respectively. Using ANOVA displayed in Table 5, observations revealed that the maximum contribution was made by the feed rate of $36.25 \%$ with depth of cut and cutting speed accounting for $33 \%$ and $28.4 \%$ respectively. The objective equation obtained for the model is

$$
\text { Objective function: } \begin{aligned}
\mathrm{y}= & {[7.40000000 \mathrm{e}-042.53333333 \mathrm{e}+001.66666667 \mathrm{e}+00] } \\
& * x+-0.47999999999996
\end{aligned}
$$

\subsection{For Al-HMMC with $9 \%$ reinforcements}

$\mathrm{S} / \mathrm{N}$ ratio in Table 6 response revealed that optimum machining parameters were found at speed, feed and depth of cut at $1000 \mathrm{rpm}, 0.15 \mathrm{~mm} / \mathrm{rev}$ and $0.3 \mathrm{~mm}$ respectively. By studying ANOVA results shown in Table 7, it can be observed that depth of cut had $32.81 \%$ contribution while feed rate had $24.6 \%$ contribution while cutting speed had very less contribution in minimizing SR. Hence

Table 6 Optimization of the output parameter for Al-HMMC with $9 \%$ reinforcement

\begin{tabular}{llllll}
\hline Speed & Feed & Depth of cut & $\begin{array}{l}\text { Surface } \\
\text { roughness }\end{array}$ & S/N ratio & Mean \\
\hline 1000 & 0.15 & 0.3 & 1.24 & -1.86843 & 1.24 \\
1000 & 0.15 & 0.6 & 2.33 & -7.34712 & 2.33 \\
1000 & 0.3 & 0.3 & 2.16 & -6.68908 & 2.16 \\
1000 & 0.3 & 0.6 & 3.09 & -9.79917 & 3.09 \\
1500 & 0.15 & 0.3 & 1.49 & -3.46373 & 1.49 \\
1500 & 0.15 & 0.6 & 2.87 & -9.15764 & 2.87 \\
1500 & 0.3 & 0.3 & 2.85 & -9.09690 & 2.85 \\
1500 & 0.3 & 0.6 & 2.28 & -7.15870 & 2.28 \\
\hline
\end{tabular}

Table 5 ANOVA for AI-HMMC with $6 \%$ reinforcement

\begin{tabular}{lllllll}
\hline Source & DF & SS & MS & F & P & Contribution (\%) \\
\hline Speed & 1 & 0.29645 & 0.29645 & 48.20 & 0.002 & 28.396953388 \\
Feed & 1 & 0.37845 & 0.37845 & 61.54 & 0.001 & 36.25173619 \\
Depth of cut & 1 & 0.34445 & 0.34445 & 56.01 & 0.002 & 32.99487523 \\
Error & 4 & 0.02460 & 0.00615 & & & 2.356434695 \\
Total & 7 & 1.04395 & & & & \\
\hline
\end{tabular}


Table 7 ANOVA for Al-HMMC with $9 \%$ reinforcement

\begin{tabular}{llllllc}
\hline Source & DF & SS & MS & F & P & Contribution (\%) \\
\hline Speed & 1 & 0.0561 & 0.0561 & 0.18 & 0.693 & 1.838681 \\
Feed & 1 & 0.7503 & 0.7503 & 2.41 & 0.195 & 24.59113 \\
Depth of cut & 1 & 1.0011 & 1.0011 & 3.22 & 0.147 & 32.81112 \\
Error & 4 & 1.2436 & 0.3109 & & & 40.75907 \\
Total & 7 & 3.0511 & & & & \\
\hline
\end{tabular}

depth of cut had the maximum contribution in turning operation to achieve minimum surface roughness. The objective equation for the Al-HMMC sample with 9\% reinforcement is is represented using dashed line. It can be grabbed from all three graphs that the minimum surface roughness was observed at a rotational speed of $1000 \mathrm{rpm}$, at feed of $0.15 \mathrm{~mm} / \mathrm{rev}$ and for a depth of cut of $0.3 \mathrm{~mm}$.

Objective function: $\mathrm{y}=[-1.20000000 \mathrm{e}-046.56666667 \mathrm{e}+006.00000000 \mathrm{e}-01] * \times+0.5050000000000332$

\subsection{Signal to noise $(\mathrm{S} / \mathrm{N})$ ratio curve}

The main effect plot for all three fabricated composites is shown in Fig. 5. The response variable variation with process parameter i.e. speed, feed, depth of cut is represented by this plot. Mean value of the response variable

\subsection{Optimization using response surface methodology (RSM)}

Table 8 shows the summary of the model developed using Response surface methodology (RSM) for the composite with $3 \%$ reinforcement. The S-value of the model helps
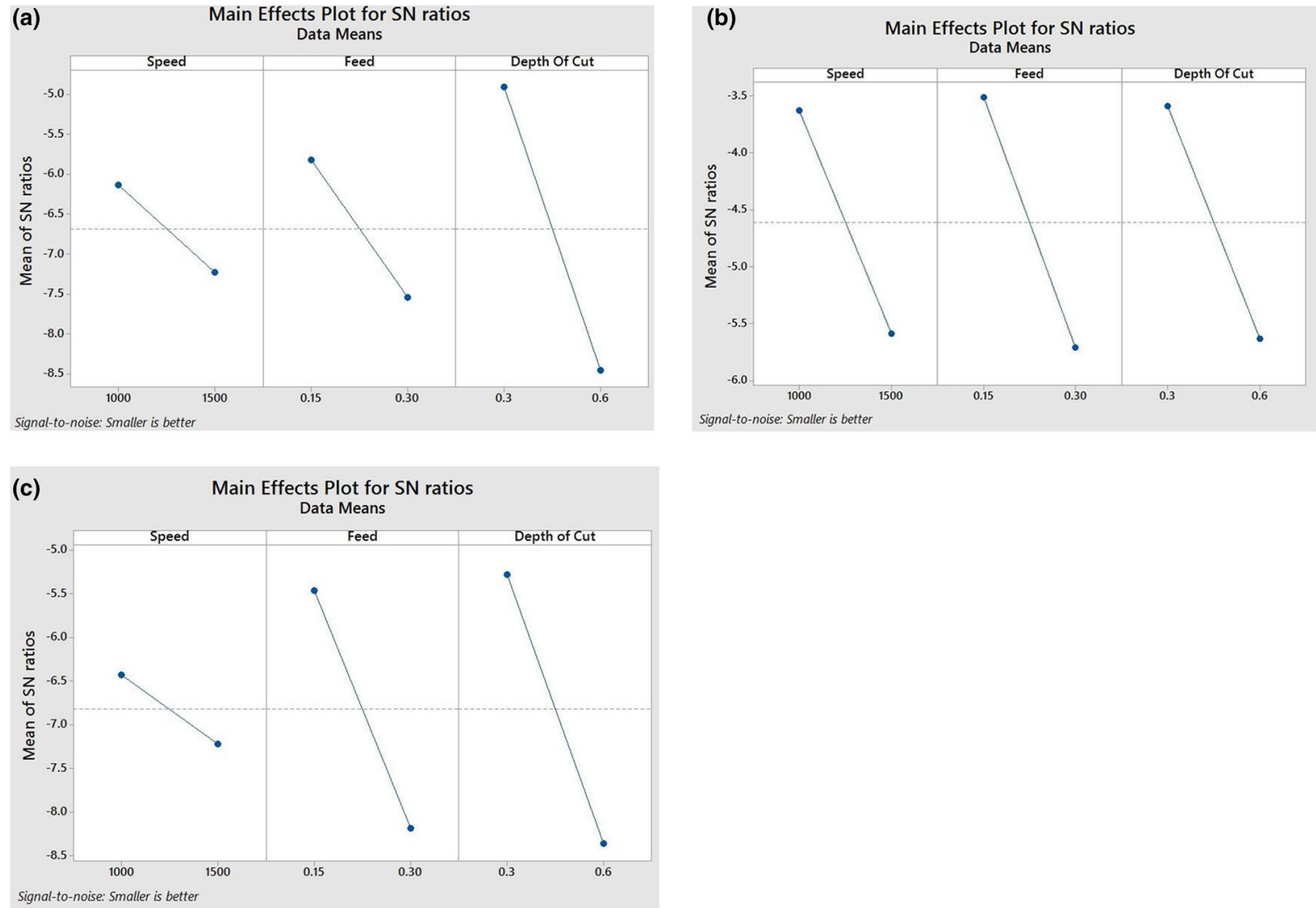

Fig. 5 Graphs of S/N ratio v/s machining parameters a Al-HMMC with $3 \%$ reinforcements $\mathbf{b}$ Al-HMMC with $6 \%$ reinforcements c Al-HMMC with $9 \%$ reinforcements 
Table 8 Model summary for Al-HMMC with 3\% reinforcement

\begin{tabular}{llll}
\hline$S$ & $R^{2}$ & $R^{2}$ (adj) & $R^{2}$ (pred) \\
\hline 0.07424 & $99.75 \%$ & $98.24 \%$ & $83.90 \%$ \\
\hline
\end{tabular}

Table 9 Model summary For Al-HMMC with 6\% reinforcement

\begin{tabular}{llll}
\hline $\mathrm{S}$ & $\mathrm{R}^{2}$ & $\mathrm{R}^{2}$ (adj) & $\mathrm{R}^{2}$ (pred) \\
\hline 0.035355 & $99.88 \%$ & $99.16 \%$ & $92.34 \%$ \\
\hline
\end{tabular}

Table 10 Model summary For Al-HMMC with 9\% reinforcement

\begin{tabular}{llll}
\hline$S$ & $R^{2}$ & $R^{2}$ (adj) & $R^{2}$ (pred) \\
\hline 0.431031 & $75.64 \%$ & $57.38 \%$ & $2.57 \%$ \\
\hline
\end{tabular}

Table 11 Optimum value for all fabricated composites

\begin{tabular}{lllll}
\hline $\begin{array}{l}\text { Reinforcement } \\
\text { percentage }\end{array}$ & $\begin{array}{l}\text { Speed } \\
\text { (rpm) }\end{array}$ & $\begin{array}{l}\text { Feed } \\
(\mathrm{mm} / \mathrm{rev})\end{array}$ & $\begin{array}{l}\text { Depth of } \\
\text { cut }(\mathrm{mm})\end{array}$ & $\begin{array}{l}\text { SR fit } \\
\text { (micrometers) }\end{array}$ \\
\hline 3 & 1000 & 0.15 & 0.3 & 1.48625 \\
6 & 1000 & 0.15 & 0.3 & 1.1875 \\
9 & 1000 & 0.15 & 0.3 & 1.01625 \\
\hline
\end{tabular}

us examine the capability of the model in describing the response. The lower the value, the better it is. For the model developed the obtained $S$ value is $0.07424 . R^{2}$ and $R^{2}$ (adj) values which are used for comparing the result of various models are $99.75 \%$ and $98.24 \%$ respectively for the developed model. The higher these values the better the fit is. $R^{2}$ (pred) is used for predicting the output based on new data. The $R^{2}$ (pred) values are given as $83.9 \%$ which is not too less than the $R^{2}$ value signifies that the model does not overfit. However, if $R^{2}$ (pred) value is significantly less than the $R^{2}$ value, it may result in overfit.

The $S$ value displayed in Table 9, for the model developed for composite with $6 \%$ reinforcement is 0.035355 . $R$-sq and $R^{2}$ (adj) values are $99.88 \%$ and $99.16 \%$ respectively, resembling that this model fits well and is capable of predicting the output based on new data. $R^{2}$ (pred) is not much less than $R$-sq value value signifying that model does not overfits.

The $S$ value is 0.431031 as shown in Table $10 . R^{2}$ and $R^{2}$ (adj) values are $75.64 \%$ and $57.38 \%$ respectively, these are high showing that developed model fits well. The $\mathrm{R}$-sq(pred) value is $2.57 \%$, signifying that the model developed overfits and is not capable of predicting the output. The predicted optimum value by RSM for composite with $3 \%, 6 \%, 9 \%$ reinforcement is shown in Table 11 . For all three composites the optimum process parameters are speed $1000 \mathrm{rpm}$, feed $0.15 \mathrm{~mm} / \mathrm{rev}$ and a depth of cut of $0.3 \mathrm{~mm}$. The same optimum parameters are displayed in Fig. 6.

\subsection{Optimization using genetic algorithm (GA)}

Table 12 displays the optimum process parameters for all fabricated composite. The genetic algorithm gave the optimized results within 102 generations which is considered to be quite fast. The optimized value of the surface roughness for Al-HMMC with 3\% reinforcement was 0.995 micrometres, while for the $6 \%$ and $9 \%$ Al-HMMC it was 1.14 and 1.49 micrometres respectively.

\section{Conclusions}

From this research work we can conclude following:

- Signal to noise ratio were calculated for evaluation of effect on surface roughness upon varying the machining variables. The Higher value of ratio of signal to noise corresponded to optimized value of that particular machining parameter.

- For Al6063-3\%(SCA-GSA-JA) and Al6063-9\%(SCA-GSA$J A$, minimum level values were optimum. Depth of cut had the maximum contribution in minimization of surface roughness.

- For Al6063-6\%(SCA-GSA-JA), minimum level values were optimum. Feed rate was majorly responsible for minimization of surface roughness.

- There was a similar pattern in all three cases as can be observed through graphs plotted except the most significant factor which varied in case of Al6063-6\%(SCAGSA-JA) hybrid metal matrix composite where feed rate was most significant factor and may be attributed to various methods of formation of chips at different values of feed rate. In A16063-3\%(SCA-GSA-JA) and Al6063-9\%(SCA-GSA-JA), highest average $S / N$ ratio was obtained for depth of cut and thus it was the most significant factor in optimization of turning process.

- The optimization results obtained using GA, closely agreed with the results from the main effects plot. For $3 \%$ reinforcement, the value of the optimized output was 0.995 at minimum level values for the inputs. For $6 \%$ reinforcement, the value of the optimized output was 1.14 at minimum values of the input. For $9 \%$ reinforcement the optimized value of the output is 1.49 at input values of $1425.71 \mathrm{rpm}$ for speed and lowest range inputs of feed and depth of cut.

- The genetic algorithm optimization for samples with $3 \%, 6 \%$ and $9 \%$ reinforcement took 102 generations to complete which is quite fast. 


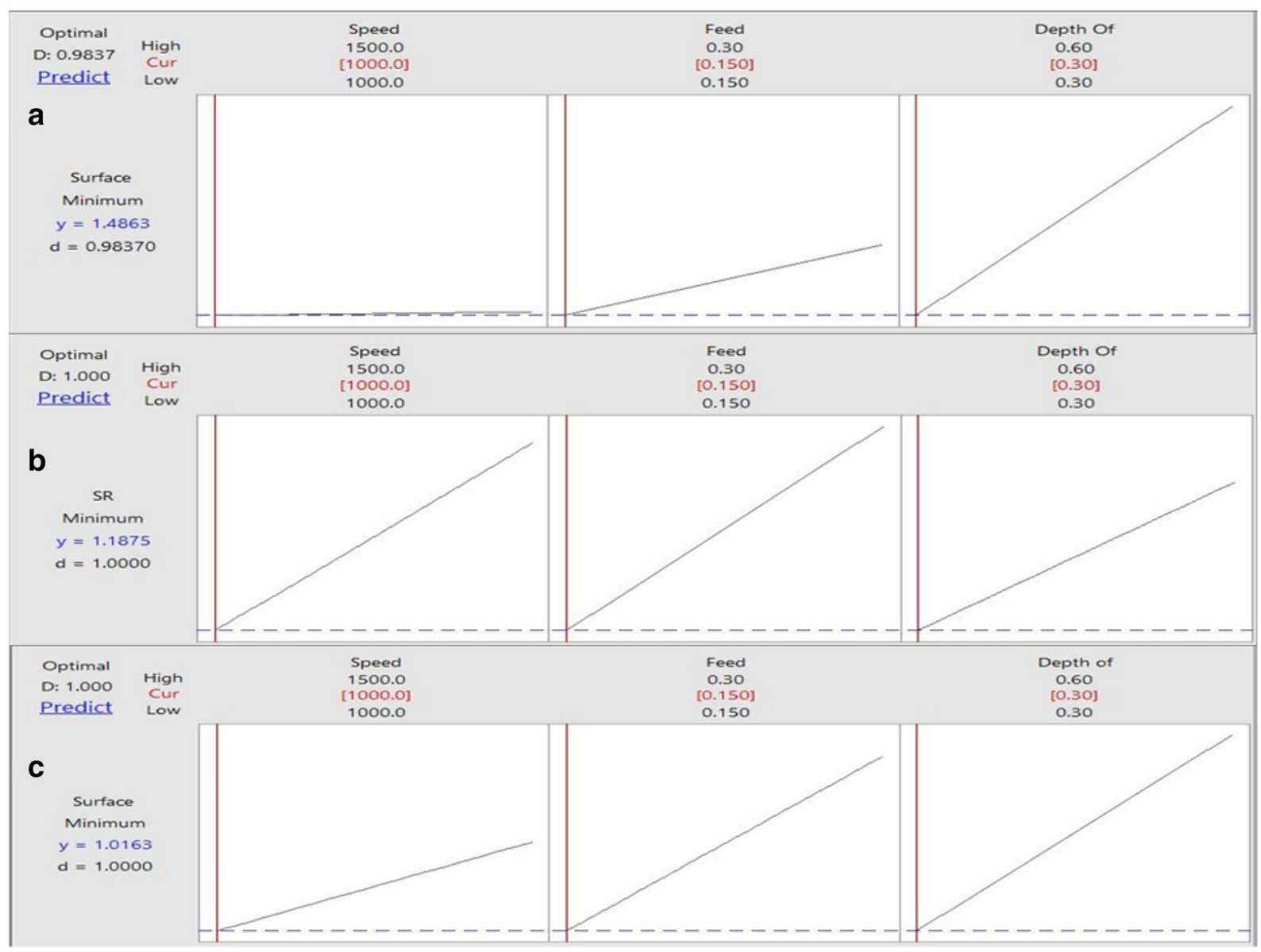

Fig. 6 Optimized value of input parameters for corresponding optimized output value. a Al-HMMC with $3 \%$ reinforcements $\mathbf{b}$ Al-HMMC with $6 \%$ reinforcements $\mathrm{c}$ Al-HMMC with $9 \%$ reinforcements

Table 12 GA optimized input factors

\begin{tabular}{llllll}
\hline $\begin{array}{l}\text { Reinforcement } \\
\text { percentage }\end{array}$ & $\begin{array}{l}\text { No of gen- } \\
\text { erations }\end{array}$ & $\begin{array}{l}\text { Optimal response vari- } \\
\text { able value (microm- } \\
\text { eters) }\end{array}$ & $\begin{array}{l}\text { Optimal } \\
\text { speed value } \\
\text { (rpm) }\end{array}$ & $\begin{array}{l}\text { Optimal feed } \\
\text { value (mm/ } \\
\text { rev) }\end{array}$ & $\begin{array}{l}\text { Optimal depth } \\
\text { of cut value } \\
\text { (mm) }\end{array}$ \\
\hline 3 & 102 & 0.995 & 1000 & 0.15 & 0.3 \\
6 & 102 & 1.14 & 1000 & 0.15 & 0.3 \\
9 & 102 & 1.49 & 1425.47 & 0.15 & 0.3 \\
\hline
\end{tabular}

- The optimal value of input parameters given by RSM were $1000 \mathrm{rpm}$ speed, $0.15 \mathrm{~mm} / \mathrm{rev}$ feed and $0.3 \mathrm{~mm}$ depth of cut for all three compositions. For the $3 \%$ reinforcement sample, SR predicted was 1.48 micrometers. For the $6 \%$ sample it was 1.18 micrometers and for the $9 \%$ reinforcement it was 1.01 micrometers.

- Results obtained from Response Surface Methodology (RSM) closely agree with GA.
Funding The authors declare that they did not receive any funding for this research.

\section{Compliance with ethical standards}

Conflict of interest The authors declare that they have no conflict of interest. 


\section{References}

1. Kar C, Surekha B, Jena H, Choudhury SD (2018) Study of influence of process parameters in electric discharge machining of aluminum - red mud metal matrix. Procedia Manuf 20:392-399

2. Kainer U (2006) Metal matrix composites: custom-made materials for automotive and aerospace engineering. Wiley, Hoboken

3. Suresh S, Mortensen A, Needleman A (1993) Fundamentals of metal matrix composites. Butterworth-Heinemann, London

4. Chawla N, Shen Y (2011) Mechanical behavior of particle reinforced metal matrix composite. Adv Eng Mater 3(6):357-370

5. Qian LH, Wang ZG, Toda H, Kobayashi T (2003) Effect of reinforcement volume fraction on the thermo-mechanical fatigue behavior of $\mathrm{SiC}_{\mathrm{W}} / 6061 \mathrm{Al}$ composites. Mater Sci Eng A 357(1-2):240-247

6. Sankaranarayanan S, Karthigeyan R, Ranganath G (2012) Mechanical properties and microstructure studies of aluminium (7075) alloy matrix composite reinforced with short basalt fibre. Eur J Sci Res 68(4):606-615

7. Swamy ARK, Ramesha A, Kumar GBV, Prakash JN (2011) Effect of particulate reinforcements on the mechanical properties of Al6061-WC and Al6061-Gr MMCs. J Miner Mater Charact Eng 10(12):1141-1152

8. Ahmad SNAS, Hashim J, Ghazali MI (2007) Effect of porosity on tensile properties of cast particle reinforced MMC. J Compos Mater 41(5):575-589

9. Vinod B, Ramanathan S, Anandajothi M (2019) A novel approach for utilization of agro-industrial waste materials as reinforcement with $\mathrm{Al}-7 \mathrm{Si}-0.3 \mathrm{Mg}$ matrix hybrid composite on tribological behaviour. SN Appl Sci 1:62. https://doi.org/10.1007/ s42452-018-0066-Z

10. Ashish George J, Lokesha K (2019) Optimisation and effect of tool rake and approach angle on surface roughness and cutting tool vibration. SN Appl Sci 1:1133. https://doi.org/10.1007/ s42452-019-1175-z

11. Coyal A, Yuvaraj N, Butola R, Tyagi L (2020) An experimental analysis of tensile, hardness and wear properties of aluminium metal matrix composite through stir casting process. SN Appl Sci 2:892. https://doi.org/10.1007/s42452-020-2657-8

12. Butola R, Pratap C, Shukla A, Walia R (2019) Effect on the mechanical properties of aluminum-based hybrid metal matrix composite using stir casting method. Mater Sci Forum 969:253259. https://doi.org/10.4028/www.scientific.net/MSF.969.253

13. Kumarasamy SP, Vijayananth $K$, Thankachan T, Muthukutti GP (2017) Investigations on mechanical and machinability behavior of aluminum/flyash cenosphere/Gr hybrid composites processed through compocasting. J Appl Res Technol 15:430-441

14. Butola R, Ranganath MS, Murtaza Q (2019) Fabrication and optimization of AA7075 matrix surface composites using Taguchi technique via Friction stir processing (FSP). Eng Res Express 1(2):025015

15. Garg MP, Sharma A (2017) Examination of accuracy aspect in machining of $\mathrm{ZrSiO}_{4 \mathrm{p}} / 6063$ aluminium MMC using $\mathrm{CNC}$ wire electrical discharge machining. Compos Commun 6:6-10

16. Dinaharan I, Kalaiselvan K, Murugan N (2017) Influence of rice husk particles on microstructure and tensile behavior of AA6061 aluminium matrix composites produced using friction stir processing. Compos Commun 3:42-46

17. Adarsha Kumar K, Ratnam C, Venkata Rao K et al (2019) Experimental studies of machining parameters on surface roughness, flank wear, cutting forces and work piece vibration in boring of
AISI 4340 steels: modelling and optimization approach. SN Appl Sci 1:26. https://doi.org/10.1007/s42452-018-0026-7

18. Butola R, Kumar J, Khanna V, Ali P, Khanna V (2017) Effect on surface properties of mild steel during dry turning \& wet turning on lathe. Mater Today Proc 4:7892-7902

19. Kumar NGS, Shankar GS, Ganesh MN, Vibudha LK (2017) Experimental investigations to study the cutting force and surface roughness during turning of aluminium metal matrix hybrid composites. Mater Today Proc 4:9371-9374

20. Nataraj M, Balasubramanian K (2017) Parametric optimization of CNC turning process for hybrid metal matrix composite. Springer, Berlin

21. Priyadarshi D, Sharma RK (2015) Optimization for turning of Al-6061-SiC-Gr hybrid nanocomposites using response surface methodologies. Mater Manuf Processes 31:1342-1350

22. Bains PS, Sidhu SS, Payal HS (2016) Fabrication and machining of metal matrix composites: a review. Mater Manuf Processes 31:553-573

23. Pul M (2013) The effect of $\mathrm{MgO}$ ratio on surface roughness in Al-MgO composites. Mater Manuf Processes 28:963-968

24. Suresh R, Basavarajappa S, Gaitonde VN, Samuel GL (2012) Machinability investigations on hardened AISI 4340 steel using coated carbide insert. Int J Refract Met Hard Mater 33:75-86

25. Sharma V, Butola R (2017) Optimization of machining parameters in CNC turning of hybrid metal matrix composites using different techniques: a review. Int J Adv Res Innov 5(1):78-82

26. Baburaj E, Sundaram KMM, Senthil P (2016) Effect of high speed turning operation on surface roughness of hybrid metal matrix composite. Springer, Berlin, pp 89-95

27. Dinaharan I, Akinlabi ET (2018) Low cost metal matrix composites based on aluminum, magnesium and copper reinforced with fly ash prepared using friction stir processing. Compos Commun 9:22

28. Butola R, Murtaza Q, Walia R, Kumar P (2017) Two start and three start helical abrasive flow machining for brittle materials. Mater Today Proc 4:3685-3693. https://doi.org/10.1016/j.matpr.2017. 02.263

29. Sonowal D, Nath T, Sarma D (2015) A review on optimization of cutting parameters on turning. Int J Eng Trends Technol 28:54-60

30. Sharma P, Sharma S, Khanduja D (2015) A study on microstructure of aluminium matrix composites. J Asian Ceram Soc 3(3):240-244

31. David G (1989) Genetic algorithms in search, optimization and machine learning. Addison-Wesley Publishing Company Inc, Reading

32. Carroll DL (1996) Chemical laser modeling with genetic algorithms. Am Inst Aeronaut Astronaut (AIAA J) 34:338-346

33. Winter G, Cuesta P, Periaux J (1996) Genetic algorithm in engineering and computer science. Wiley, New York

Publisher's Note Springer Nature remains neutral with regard to jurisdictional claims in published maps and institutional affiliations.

Springer Nature or its licensor (e.g. a society or other partner) holds exclusive rights to this article under a publishing agreement with the author(s) or other rightsholder(s); author self-archiving of the accepted manuscript version of this article is solely governed by the terms of such publishing agreement and applicable law. 